\title{
Complutum
}

ISSN: 1131-6993

\section{Enfoques sobre el patrimonio arqueológico y su impacto en el sistema legal de los países sudamericanos ${ }^{1}$}

\author{
María Luz Endere ${ }^{2}$
}

Recibido: 18/02/2021 / Aceptado: 30/07/2021

Resumen. Un análisis de la legislación aplicable al patrimonio arqueológico de los países sudamericanos permite reconocer características comunes e identificar la alternancia de ciertas miradas y enfoques que han marcado tendencia en diferentes períodos de tiempo. En orden cronológico, es posible distinguir tres Modelos de Protección del Patrimonio Arqueológico, denominados Tradicional, Transicional y Tendencial, los cuales han tenido predominancia en los sistemas legales de los países sudamericanos. El objetivo de este trabajo consiste en caracterizar esos modelos y ejemplificarlos con las normas legales de los principales países de la región, para luego discutir las tendencias actuales en vista al futuro próximo. Se tomarán en consideración algunas disposiciones legales de Argentina, Brasil, Bolivia, Colombia, Chile, Ecuador, Paraguay, Perú, Uruguay y Venezuela. Para realizar esta investigación, se efectúo un análisis de las fuentes legales disponibles en repositorios digitales y de bibliografía especializada. Como resultado, se destaca la supervivencia actual del Modelo Tradicional con agregados temáticos propios de los modelos posteriores, así como la creciente complejidad que la problemática indígena trae a la gestión -cuando no a la propiedad misma-del patrimonio arqueológico, al tiempo que la participación comunitaria sigue siendo un objetivo a alcanzar.

Palabras clave: Patrimonio Arqueológico, Legislación, Gestión, Participación, Derechos indígenas.

\section{[en] Approaches on the Archaeological Heritage and its Impact on the Legal System of South American Countries}

\begin{abstract}
An analysis of the legislation applied to the archaeological heritage in South American countries allows to recognize common characteristics and identify the alternation of certain views and approaches that have marked a trend in different periods of time. In chronological order, it is possible to distinguish three Models of Archaeological Heritage Protection, named Traditional, Transitional and Tendential, which have been predominant in the legal systems of the South American countries. The objective of this paper is to characterize these models and exemplify them with the legal regulations of the main countries in the region, and then discuss current trends and future prospects. Some legal provisions of Argentina, Brazil, Bolivia, Colombia, Chile, Ecuador, Paraguay, Peru, Uruguay and Venezuela will be taken in consideration. In order to carry out this research, an analysis of the legal sources available in digital repositories and specialized bibliography was carried out. As a result of this study, the current survival of the Traditional Model with thematic additions typical of later models stands out, as well as the increasing complexity that indigenous issue bring to the management -if not to the property itself- of the archaeological heritage, while community participation is still a goal to be achieved.
\end{abstract}

Keywords: Archaeological heritage, Legislation, Management, Participation, Indigenous rights.

Sumario. 1. Introducción. 2. Modelo tradicional de protección del patrimonio arqueológico. 3. Modelo transnacional: nuevos actores en la escena patrimonial. 4. Modelo tendencial: navegando entre corrientes antagónicas. 5. Comentarios finales. Bibliografía.

1 Agradecimientos. Este trabajo fue realizado en el marco de las investigaciones desarrolladas por PATRIMONIA (Programa Interdisciplinario de Estudios del Patrimonio) del Instituto INCUAPA (U.E. CONICET - UNICEN) y fue financiado a través de los proyectos PIP 106/15 CONICET y PICT 0551/16 ANPCyT, ambos dirigidos por la autora.

2 PATRIMONIA-INCUAPA (UE CONICET-UNICEN)

Estudios Interdisciplinarios de Patrimonio (PATRIMONIA), Instituto de Investigaciones Arqueológicas y Paleontológicas del Cuaternario Pampeano (INCUAPA), Unidad Ejecutora del CONICET - Universidad Nacional del Centro de la Provincia de Buenos Aires (UNICEN). Facultad de Ciencias Sociales. Avda. del Valle 5737 - 7400 Olavarría - Argentina mendere@spc.unicen.edu.ar - +54-2284-450115 int.8111 
Como citar: Endere, M. L. (2021): Enfoques sobre el patrimonio arqueológico y su impacto en el sistema legal de los países sudamericanos. Complutum, 32(2): 657-671.

\section{Introducción}

Los sistemas legales nacionales son el producto de un sinnúmero de factores políticos, sociales e ideológicos que influyen en la elaboración de los proyectos de leyes, así como en todas las instancias posteriores hasta la aprobación del texto definitivo de las normas, incluyendo el debate en comisiones parlamentarias y en el propio recinto de las cámaras. En algunos países no existe una norma general de patrimonio cultural sino una sumatoria de disposiciones de diferente alcance que fueron dictadas a través del tiempo y que constituyen, a la postre, un conjunto no siempre coherente de normas patrimoniales. No obstante, si se analizan la legislación aplicable al patrimonio arqueológico en los países sudamericanos es posible reconocer algunas características comunes e identificar, además, la alternancia de ciertas miradas $y$ enfoques que han marcado tendencia en diferentes períodos de tiempo. Así, la recepción de esos enfoques en las normas patrimoniales permite distinguir, en un orden cronológico, al menos tres grandes modelos que se han tenido predominancia en los sistemas legales de la región y que han sido identificados en el marco de este análisis como Modelos Tradicional, Transicional y Tendencial. En este sentido, el objetivo de este trabajo consiste en caracterizar estos tres modelos y ejemplificarlos con las normas legales de los principales países sudamericanos, para luego discutir las tendencias actuales y las perspectivas que se vislumbran para el futuro próximo. Se tomarán como ejemplo algunas disposiciones legales de Argentina, Brasil, Bolivia, Colombia, Chile, Ecuador, Paraguay, Perú, Uruguay y Venezuela. Para ellos se efectúo un análisis de las fuentes legales disponibles en repositorios digitales y de bibliografía especializada.

\section{Modelo tradicional de protección del patrimonio arqueológico}

Desde fines del siglo XIX y fundamentalmente durante el siglo XX, en el contexto de consolidación de las naciones sudamericanas, la construcción de una historia nacional y de un patri- monio que le diera a ella un sustrato material constituyó una verdadera política de estado (Endere 2009, ver también Hobsbawm y Ranger 1983; Prats 1997). En ese marco comenzó a configurarse lo que podría denominarse el Modelo Tradicional de protección legal del patrimonio, caracterizado por la sanción de normas generales o especiales que declaraban el dominio público de Estado (nacional y provincial o estadual) sobre el patrimonio arqueológico incluyendo los sitios - también llamados yacimientos- y las colecciones. Asimismo se regulaba las expediciones arqueológicas y los permisos de exploración y excavación con un doble fin: desalentar a los buscadores de tesoros, tradicionalmente llamados huaqueros, por un lado, y monitorear la actividad de investigadores y misiones extranjeras, por otro, normalmente exigiendo una contraparte nacional y fiscalizando la salida de piezas del país (Endere y Bonnin 2020). Este modelo establecido a través de las normas consolidó dos aspectos fundamentales: la estatización del patrimonio arqueológico y la profesionalización de la actividad. Cabe recordar que en un principio más que el requisito del título académico, lo que se exigía y/o reconocía era la filiación institucional a algún museo o instituto reconocido, usualmente de carácter estatal. No obstante, debe reconocerse que ese modelo no siempre fue respetado en la práctica y su falta de observancia permitió que el patrimonio siguiera fluyendo en manos privadas sin mayores dificultades, aunque ya con la impronta de lo ilegal.

Las características fundamentales de ese modelo siguen vigentes, como la propiedad estatal sobre el patrimonio arqueológico cuyos bienes son declarados inajenables, inembargables e imprescriptibles. Así, en Argentina, las ruinas y yacimientos arqueológicos pertenecen al dominio público del Estado desde 1913. Actualmente ello lo establece el Código Civil y Comercial (art. 235), así como la Ley de preservación, protección y tutela del Patrimonio arqueológico 25.743/03. El patrimonio arqueológico en Brasil también es propiedad del Estado (art. 20, X de la Constitución Federal de 1988, art. 1.230 del Código Civil C y el art. 1 de la Ley 3.924/61). Esta última norma hace referencias a monumentos y yacimientos 
arqueológicos o prehistóricos, incluyendo cementerios indígenas, sambaquis, abrigos rocosos, sitios cerámicos, líticos o con pinturas rupestres, entre otros, así como sus colecciones (Endere et al. 2011). La Constitución de Bolivia de 2008 declara que la riqueza arqueológica es patrimonio cultural del pueblo boliviano (art. 99) y, la Ley de Patrimonio Cultural 530/14 establece que el Patrimonio Arqueológico es de propiedad del Estado, estableciendo que "esta propiedad es colectiva; ninguna persona o institución pública o privada puede reclamarlo a título personal. Los poseedores de estos bienes culturales, anteriores a la promulgación de la presente Ley, se constituyen en custodios" (art. 13). La Constitución de Colombia de 1991 establece que el patrimonio arqueológico pertenece a la Nación y los bienes que lo integran son inalienables, inembargables e imprescriptibles (arts. 63, ver también Ley de Cultura 397/97 y sus modificatorias) aunque especifica que una ley reglamentará los derechos especiales que pudieran tener los grupos étnicos asentados en territorios de riqueza arqueológica (art. 72). En Chile, la Ley 17.288/70 de Monumentos Nacionales (modificada por Ley 21.045/17) establece que "los monumentos arqueológicos son propiedad del Estado por el sólo ministerio de la ley", entre ellos se incluyen a "los lugares, ruinas, yacimientos y piezas antropo-arqueológicas que existen sobre o bajo la superficie del territorio nacional" (art. 21) y "los enterratorios o cementerios u otros restos de los aborígenes" (art. 1). La Constitución Nacional de Ecuador de 2008 incluye entre los bienes que integran el patrimonio cultural tangible e intangible a aquellos que tengan valor arqueológico (art. 379 inc. 2). Las áreas arqueológicas que se encuentren en propiedad pública o privada deberán ser delimitadas y estarán sujetas a la protección del Estado, a su vez los objetos arqueológicos son propiedad exclusiva del Estado ecuatoriano (art 65 de la Ley Orgánica de Cultura de 2016). Se declara que "los bienes culturales patrimoniales del Estado serán inalienables, inembargables e imprescriptibles. El Estado tendrá derecho de prelación en la adquisición de los bienes del patrimonio cultural y garantizará su protección. Cualquier daño será sancionado de acuerdo con la ley" (art. 379 in fine CN, art. 64 Ley Orgánica de Cultura SAN-2016-2272). En Paraguay, la Ley 5.621/16 de Protección de Bienes Culturales establece que el patrimonio arqueológico es del dominio del Estado (art. 5 i). La Constitución de Perú declara que los yacimientos y restos arqueológicos son Patrimonio Cultural de la Nación y están protegidos por el Estado (art. 21). Ley General del Patrimonio Cultural 28.296/07 de Perú especifica los sitios arqueológicos prehispánicos son de propiedad del Estado, así como sus partes integrantes, sean descubiertos o por descubrir y tienen la condición de propiedad intangible, inalienable e imprescriptible (art. 6). La Constitución Nacional de Uruguay establece que "toda la riqueza artística o histórica del país, sea quien fuere su dueño, constituye el tesoro cultural de la Nación; estará bajo la salvaguardia del Estado y la ley establecerá lo que estime oportuno para su defensa" (art. 34). El patrimonio cultural de ese país es regulado por la Ley $\mathrm{N}^{\circ} 14.040 / 71$ y su Decreto Reglamentario 536/72 que estatuye que "las piezas arqueológicas serán propiedad del estado" (art. 9). Finalmente la Constitución de Venezuela de 1999 declara inalienables, imprescriptibles e inembargables los bienes que constituyen el patrimonio cultural de la Nación (art. 99), mientras que la Ley de Patrimonio 4.623 ratifica la propiedad del Estado sobre el patrimonio arqueológico que fuese descubierto en el suelo, el subsuelo y las zonas subacuáticas (art. 35).

En la segunda mitad del siglo XX, la actividad de UNESCO y la ratificación de las Convenciones de 1954, 1970 y 1972, así como de la OEA de $1976^{3}$, por parte de los estados sudamericanos, contribuyó a consolidar la agenda patrimonial nacional tanto como a consolidar el poder estatal no sólo como titular del dominio sino también como gestor patrimonial. En esta tarea los Estados contaron con el auxilio

Argentina, Bolivia, Brasil, Chile, Colombia, Ecuador, Paraguay, Perú, Venezuela y Uruguay son Estados miembros de la Convención para la Protección de los Bienes Culturales en caso de Conflicto Armado de UNESCO de 1954; la Convención sobre las Medidas que Deben Adoptarse para Prohibir e Impedir la Importación, la Exportación y la Transferencia de Propiedad Ilícitas de Bienes Culturales de UNESCO de 1970, la Convención para la Protección del Patrimonio Mundial Cultural y Natural de UNESCO de 1972 y la Convención para la Salvaguardia del Patrimonio Cultural Inmaterial de UNESCO de 2003. La Convención sobre la Protección del Patrimonio Cultural Subacuático de UNESCO de 2001 fue ratificada por Argentina, Bolivia, Ecuador y Paraguay. La Convención de UNIDROIT sobre los Bienes Culturales Robados o Exportados Ilícitamente de 1995 fue ratificada por Argentina, Brasil, Bolivia, Colombia, Ecuador, Paraguay y Perú. La Convención sobre Defensa del Patrimonio Arqueológico, Histórico y Artístico de las Naciones Americanas de 1976 fue ratificada por Argentina, Bolivia, Ecuador, Paraguay y Perú. 
de los expertos que, en algunos casos, llegaron a ocupar puestos en la administración pública nacional o local, contribuyendo a la profesionalización de la administración del patrimonio. Así, el surgimiento de organismos públicos especializados en la gestión del patrimonio es otra característica común, aunque el impacto de los mismos difiere en aquellos países donde la gestión del patrimonio es descentralizada. En Argentina actualmente, por ejemplo, las competencias sobre esta materia son locales, por lo que el accionar de las autoridades de aplicación provinciales es el que tiene mayor incidencia sobre el patrimonio arqueológico, mientras que el papel que desempeña el Instituto Nacional de Antropología y Pensamiento Latinoamericano (INAPL) como la autoridad federal encargada de su protección en la práctica está más desdibujado. En contraposición, los países que cuentan con organismos con competencias exclusivas en todo el territorio nacional (e.g. Instituto Colombiano de Antropología e Historia, el Consejo de Monumentos Nacionales de Chile, Instituto Nacional de Patrimonio Cultural de Ecuador, el Ministerio de Cultura de Perú4, la Comisión de Patrimonio Cultural de la $\mathrm{Na}$ ción de Uruguay, entre otros) tienen mayores posibilidades de diseñar y poner en práctica políticas, planes, programas y proyectos. Por su parte Brasil, pese a ser un estado federal, tiene un organismo autárquico que se ocupa del patrimonio denominado Instituto de Patrimonio Histórico y Artístico Nacional (IPHAN) que cuenta con representaciones regionales en todo el territorio nacional, así como con sectores específicos para la protección del patrimonio material mueble, inmueble y museos (Saladino y Moraes Wichers 2015).

\section{Modelo transnacional: nuevos actores en la escena patrimonial}

La década de 1980 estuvo signada por importantes cambios que generaron las condiciones para el surgimiento de un modelo de protección del patrimonio denominado Transicional.

Este Ministerio fue creado en 2010 mediante la Ley 29.565. Anteriormente la autoridad de aplicación era el Instituto Nacional de Cultura del Perú (INC) que poseía un rango ostensiblemente menor. Este instituto había sido creado en 1972 mediante el Decreto Ley 18.799 y tenía el carácter de un organismo descentralizado, con autonomía técnica, administrativa, económica y financiera. Su estructura fue absorbida por el nuevo ministerio.
En esa década tuvieron su epílogo los gobiernos dictatoriales que habían manejados los destinos de la mayoría de las naciones sudamericanas durante las décadas previas. La posibilidad de efectuar elecciones libres significó la vuelta de la democracia en la región. Los nuevos gobiernos pronto pusieron en agenda reformas constituciones con el objetivo de incorporar nuevas categorías de derechos, en especial los de incidencia colectiva, como los relativos a la paz, al ambiente sano y al patrimonio cultural. Asimismo se produjo un reconocimiento expreso a la diversidad cultural, los derechos de los pueblos indígenas y/o de los afrodescendientes. Ejemplo de ellos son las constituciones de Argentina, Bolivia, Brasil, Colombia, Ecuador, Paraguay, Perú y Venezuela que fueron reformadas en las últimas cuatro décadas (Barié 2003). En 2020 se aprobó en Chile, mediante un plebiscito, la reforma de la constitución nacional a realizarse mediante una convención constituyente, siendo uno de los temas a tratar $-y$ objeto de reclamos- el reconocimiento de los derechos de los pueblos indígenas. Cabe destacar que este país cuenta con una ley indígena desde 1993 (Ley 19.253). Uruguay ha iniciado un proceso de reconocimiento de los derechos de los pueblos indígenas, previamente considerados inexistentes en el territorio. En 2009 se aprobó mediante la Ley 18.589 la conmemoración del Día de la Nación Charrúa e Identidad Indígena cada 11 de abril (Endere 2020a).

Como puede observarse, durante este período se evidencia el surgimiento de los pueblos indígenas como nuevos actores políticos, amparados por las normas nacionales de autoreconocimiento étnico y el Convenio 169 de la OIT que ha sido ratificado por todos los países antes mencionados, con excepción de Uruguay. Ello contribuyó a fortalecer los reclamos de los pueblos indígenas sobre el patrimonio cultural y sobre los restos humanos de sus antepasados que forman parte de colecciones de museos. La cuestión de la restitución o repatriación y eventual reenterramiento de restos humanos ha sido un tema particularmente importante en Chile y Argentina, países que cuentan ya con una vasta experiencia en el tema (Endere 2020b; Arthur y Ayala 2021). Así la potestad estatal sobre el patrimonio comenzó a ser cuestionada por las minorías étnicas (en muchos de estos países lo son en relación a su acceso al poder más que en sentido numérico), mientras que la gestión patrimonial empezó a ser desafiada por la ciu- 
dadanía en general que le reclama su falta de acción o su negligencia en la salvaguarda de los bienes culturales. Si bien hay una enorme variabilidad entre las gestiones patrimoniales de los diferentes países, el reclamo ciudadano es una constante, muchas veces encarnado en las voces de académicos y expertos que hacen públicas sus opiniones o de vecinos y de los propios medios de comunicación que reaccionan frente a casos puntuales que atraen la atención pública como robos o saqueos ${ }^{5}$.

A su vez y, como eco de fenómenos que se dieron a escala mundial, ya para la década de 1990 las evaluaciones de impacto ambiental comenzaron a ser contempladas en la normativa de los países de la región. En ese marco se exigieron, con mayor o menor grado de especificidad y de eficacia, los estudios de impacto sociocultural y arqueológico, así como los eventuales rescates. El efecto que ha tenido la arqueología de contrato ha variado en cada país e incluso en diferentes regiones dentro de cada uno de ellos. Sin embargo, la característica común es la aparición de otros actores en escena, en especial la empresa contratista, cuyo accionar suele tener en la práctica una enorme influencia en las condiciones en que se logra salvaguardar el patrimonio. Es interesante observar cómo este nuevo actor contribuyó a reconfigurar el rol del Estado -ahora convertido en fiscalizador- y de los profesionales de la arqueología, devenidos en consultores.

Cabe destacar que estos cambios lejos de diluirse se fueron consolidando en el tiempo. Argentina es uno de los países donde la arqueología preventiva ha tenido menos impacto en el mercado laboral. La ley nacional de patrimonio arqueológico sólo se limita a exigir la denuncia del hallazgo y la conservación a quien practicase excavaciones con el objeto de efectuar trabajos de construcción, agrícolas, industriales o de otro tipo (Ley 25.743/03 art. 13). No obstante, el Decreto Reglamentario 1.022/04 contempla la suspensión de toda actividad hasta que intervenga la autoridad competente y establece que los responsables de

\footnotetext{
Un caso paradigmático sucedió en Ecuador en 2007 a raíz del robo de una custodia de oro y piedras preciosas, obra de arte colonial, exhibida en el Convento de las Conceptas en la ciudad de Riobamba y considerada la más valiosa joya religiosa del tesoro ecuatoriano. La reacción pública frente a la noticia trajo como consecuencia la firma de un decreto por parte del Ejecutivo Nacional por el cual se ordenó y financió un inventario integral de todo el patrimonio nacional (Decreto de Emergencia del Patrimonio Cultural 816).
}

emprendimientos deberán prever la necesidad de realizar prospecciones previas al comienzo de las obras (ver art. 13). Cada provincia posee además su propia normativa patrimonial y ambiental, por lo que la situación varía notablemente de un caso a otro.

De todos modos, la envergadura de la arqueología preventiva en este país no es comparable con la que se realiza en otros de la región, notablemente Colombia, Brasil y Chile. En Brasil, la obligación de realizar evaluaciones de impacto arqueológico y rescate de sitios arqueológicos que serían destruidos por la realización de obras de infraestructura es establecida por un conjunto de normas (e.g. Portaria IPHAN 230/2002; Decreto IPHAN 28/2003, IN001/15; Ley 6.938/81 y concordantes) y se suele exigir la obligación de realizar y financiar programas de educación patrimonial (Endere et al. 2011; Saladino 2019). El aumento de los proyectos arqueológicos que generó la arqueología de contrato llevó al IPHAN a crear el Centro Nacional de Arqueología (CNA), mediante el Decreto 6.844/09, a fin de poder afrontar el volumen de actividades de evaluación, acompañamiento y fiscalización necesarias (Saladino y Moraes Wichers 2015: 53). En Colombia la Ley 397 (modificada por la Ley $1185 / 2008$, Decreto 763/09) exige una licencia ambiental como requisito previo para autorizar obras, así como la obligación de presentar a la autoridad competente en materia patrimonial (ICANH) un Plan de Manejo Arqueológico, sin cuya aprobación no podrán iniciarse las obras (ver también Decreto 138/19). Por su parte, en Chile es la Ley del Ambiente 19.300/94 la que regula los estudios de impacto, estableciendo que demandarán una evaluación de impacto ambiental las actividades que impliquen "alteración de monumentos, sitios con valor antropológico, arqueológico, histórico y, en general, los pertenecientes al patrimonio cultural" (art. 11 inc. F; art. 76 Decreto Supremo 95/01).

Como puede observarse, la efectividad de la arqueología preventiva no depende sólo de haber sido contemplada en la legislación sino también del poder de policía y de la capacidad de controlar su efectivo cumplimiento que poseen los organismos competentes. En Ecuador, la ley exige suspender la obra e informar al organismo de aplicación (INCP), quien evaluará la situación y dispondrá las acciones preventivas y correctivas necesarias (arts. 44, 77 y 85 de la Ley Orgánica de Cultura). Cabe destacar que en este país se prevé la actuación conjun- 
ta de los organismos competentes en materia patrimonial (INPC) y de Ambiente (Ministerio de Ambiente) en la elaboración de normas técnicas para la emisión de certificados, registros y licencias ambientales que requieran la ejecución de estudios de impacto arqueológico (art. 72, Decreto 1428/17). La ley de Patrimonio Cultural peruana 28.296/07 exige la intervención del Ministerio de Cultura cada vez que se proyecten obras que puedan afectar el patrimonio cultural (art. 22.1) u obras públicas de infraestructura y de servicios públicos que afecten áreas donde se encuentren bienes culturales mediante la ejecución del Proyecto de Evaluación Arqueológica (art. 22). La legislación patrimonial de Bolivia le da un tratamiento diferenciado a los proyectos de obras que afecten al patrimonio cultural, para lo cual se aprobó en 2018 un reglamento que establece las condiciones de la arqueología de contrato a realizarse en contexto de obras públicas y privadas (Res. 020/18). En Paraguay, Uruguay y Venezuela la evaluación de impacto arqueológico es regida por la legislación ambiental (e.g. en Paraguay lo establece la Ley 294/93 de Evaluación de Impacto Ambiental y el Decreto 14.281/96, siendo la Autoridad de Aplicación la Secretaría del Ambiente; en Uruguay se incluye en la evaluación de impacto ambiental la afectación de sitios de interés histórico cultural, ver Ley 16.466 y el Decreto 349/2005 art. 12.I.c). Cabe mencionar que en aquellos países donde la arqueología de contrato se desarrolló, se ha producido un aumento exponencial de colecciones arqueológicas $-y$ por ende la necesidad de disponer de espacios para almacenarlas-, sin que ello se vea reflejado en una mayor disponiblidad de información científica -producida a partir de dichas investigacionesque aporten al conocimiento del pasado. Todo ello ha motivado la urgencia por establecer directrices y principios éticos para la actividad arqueológica en estos nuevos contextos (Saladino y Moraes Wichers 2015; ver también Valdez 2010).

\section{Modelo tendencial: navegando entre corrientes antagónicas}

En el nuevo milenio se puso de manifiesto un tercer de modelo que podría denominarse Tendencial, ya que está marcado por ciertas líneas de pensamiento que han llegado a influenciar los sistemas de regulación y gestión del patrimonio de los diferentes países mencionados.

La primera de ellas está signada por el impacto que han ejercido en los sistemas normativos regionales los instrumentos de derecho internacional -como las Convenciones de UNESCO- y las normas de soft law ${ }^{6}$-como son las Directrices Operativas del Comité del Patrimonio Mundial, las Recomendaciones de UNESCO y las Cartas de ICOMOS-. Ello es particularmente evidente en el reconocimiento legal de nuevas categorías patrimoniales tales como los paisajes e itinerarios culturales. A través de la incorporación de estas nuevas categorías se pretende superar al "yacimiento" como unidad de protección (denominado "sitio" en generaciones más recientes de normas); una categoría propia del Modelo Tradicional que restringe la protección al lugar del hallazgo. Además, la posibilidad de proteger áreas en vez de puntos en el territorio, obliga a efectuar una gestión que sea capaz de visibilizar el sitio en relación con los demás componentes culturales y naturales del entorno, y compatibilizar los diferentes elementos de ese paisaje, sean antiguos o modernos.

En el contexto internacional, el concepto de paisaje cultural comenzó a ser introducido en documentos de UNESCO desde la década de 1960 (ver Levrand y Endere 2020), aunque recién en 1992 fue adoptada como categoría patrimonial por el Comité del Patrimonio Mundial. Se ha afirmado que los paisajes culturales "ilustran la evolución de la sociedad humana y sus asentamientos a lo largo del tiempo, condicionados por las limitaciones y/o oportunidades físicas que presenta su entorno natural y por las sucesivas fuerzas sociales, económicas y culturales, tanto externas como internas" (UNESCO 2005:47). En 2008 ese Comité incorporó una clasificación de paisajes culturales entre los que se incluye el paisaje cultural asociativo, que es aquel que está determinado por las asociaciones religiosas, artísticas o culturales del elemento natural más que en evidencia de tipo cultural material, que puede ser insignificante o estar ausente (UNESCO 2008: 86).

Por su parte, la Carta de ICOMOS de Itinerarios Culturales de 2008 fue clave para el reconocimiento de esta categoría patrimonial en el

Se los considera normas de soft law por poseer cierta relevancia jurídica pese a su carácter jurídicamente no vinculante, dada su influencia para orientar la creación de normas, así como instrumentos interpretativos de la legislación de los países (Levrand 2016). 
ámbito internacional. Compleja y multidimensional, se caracteriza por considerar el contexto natural y cultural, así como los componentes tangibles e intangibles y por tener un carácter dinámico. Se ha afirmado que "el concepto de Itinerario Cultural constituye un conjunto de valor superior a la suma de los elementos que lo integran y que le confiere su sentido"; que "esta amplitud es importante desde el punto de vista territorial y del tratamiento integral de los diversos elementos patrimoniales (...) $y$, que la diversidad de culturas que entraña se constituye en una alternativa a los procesos de homogeneización cultural" (ICOMOS 2008, punto 3.4). Esta carta, así como las conclusiones de otras reuniones de expertos (e.g. "Rutas como parte de nuestro patrimonio cultural" celebrada en Madrid en 1994) fueron discutidas por el Comité del Patrimonio Mundial, quien decidió incluir los itinerarios culturales en las Directrices Operativas para la nominación de sitios del patrimonio mundial de 2017. La acreditación de estas nuevas categorías por parte del mencionado Comité generó en los países sudamericanos la necesidad de actualizar sus normativas para poder ser coherentes con las nominaciones de sitios que pretendían presentar ante $\mathrm{UNESCO}^{7}$. Actualmente varios paisaje culturales sudamericanos están inscriptos en la lista del patrimonio mundial, un antecedente importante fue el Santuario Histórico de Machu Picchu nominado por Perú en 1983 y reconocido como sitio mixto, al que se sumó luego el Parque Nacional del Río Abiseo en 1990. A estos le siguieron otros paisajes igualmente reconocidos por UNESCO como el Parque Nacional Rapa Nui (Chile 1995), la Quebrada de Humahuaca (Argentina 2003), el Paisaje Cultural Cafetero (Colombia 2011) y Río de Janeiro (Brasil 2012) (ver Pérez y Fernández Salinas 2015). Estas inscripciones no están exentas de controversias y se ha puesto de relieve el impacto negativo que, al menos en algunos casos, han tenido en las poblaciones locales. En efecto, las promesas de mejora social que podrían esperarse a partir de estos proyectos patrimoniales, lejos de alcanzarse dieron por resultado la marginación de las co-

Por ejemplo, Argentina incorporó las categorías patrimoniales de paisaje cultural e itinerario cultural en la reforma a la Ley de Patrimonio Histórico y Artístico efectuada en 2015 (art. 4.12 y 4.13 de la Ley 12.665 modificada por la Ley 27.103). Bolivia, por su parte reconoció las categorías de Paisajes Culturales y Lugares Sagrados en 2019 (Ley 530 modificada por la Ley 1.220). munidades tradiciones que supuestamente se valoran en tales proyectos (Meskell 2018; ver también Ramírez Arias y Saldarriaga Rmírez 2013; Levrand 2016).

Un caso paradigmático lo constituyó todo el proceso de nominación del Qhapac Ñan o Camino Principal Andino para ser incorporado a la Lista del Patrimonio Mundial, el cual fue inscripto como itinerario cultural en 2016. Como parte de un proyecto común encabezado por Perú y seguido por Colombia, Ecuador, Argentina, Chile y Bolivia, su concreción generó una experiencia única de trabajo mancomunado y sirvió, además, como homogeneizador de criterios de gestión y salvaguarda entre los expertos y las administraciones involucradas.

En segundo lugar, se identifica el impacto de los objetivos del desarrollo sostenible sobre el patrimonio cultural como una tendencia fuerte a nivel internacional que está influyendo en la región. Cabe recordar que la Agenda 2030 para el Desarrollo Sostenible, aprobada en 2015 por los Estados Miembros de la ONU, se sintetizó en 17 Objetivos (ODS) que constituyen los desafíos más apremiantes de nuestro tiempo (Wood et al. 2018). A diferencia de los Objetivos del Milenio de 2015, la Agenda 2030 incluye a la cultura, a la que reconoce como motor y facilitador para el desarrollo sostenible. En ese marco, en la cuarta meta correspondiente al ODS 11 se exige "redoblar los esfuerzos para proteger y salvaguardar el patrimonio cultural y natural del mundo" (11.4). La inclusión de la cultura y, en su marco del patrimonio, en la Agenda 2030 fue el corolario de una estrategia llevada a cabo por UNESCO y su organismo asesor, el ICOMOS, que bregaron por posicionar a la cultura como recurso y como herramienta transversal para alcanzar el ideal transformador de dicha Agenda (UNESCO 2018). En este marco, se ha enfatizado en los diferentes documentos especializados la relación entre patrimonio y desarrollo sustentable (e.g. la Declaración de París sobre el patrimonio como motor de desarrollo de ICOMOS de 2011; la Declaración de Florencia sobre los principios y recomendaciones sobre el valor del patrimonio cultural y los paisajes para promover sociedades pacíficas y democráticas de 2014; las conclusiones de NARA + 20: sobre prácticas de patrimonio, valores culturales y el concepto de autenticidad, organizada por ICOMOS Japón en 2014; la Declaración de Hangzhou: Situar la cultura en el centro de las políticas de desarrollo sosteni- 
ble de UNESCO en 2013, citadas en Cantar et al. 2020, por sólo mencionar algunas). Como consecuencia de todo ello, no debe sorprender entonces que en las Agenda 2030 de los países de la región se haga mención al patrimonio y que las nuevas políticas de gestión patrimonial se orienten a las metas de los ODS. El tiempo dirá si ello realmente tuvo algún impacto en la práctica.

Otros cambios normativos no surgieron por influencia de organismos internacionales sino como resultado de luchas de diferentes colectivos sociales, sostenidas a veces durante décadas, en el marco de las cuales cada logro constituye en realidad un escalón más en pos de alcanzar una nueva conquista. Así, el reconocimiento pleno de la diversidad cultural de Sudamérica efectuado en las constituciones nacionales reformadas en las últimas décadas del siglo XX, así como la ratificación del Convenio 169 de la OIT ha abierto la puerta a nuevos reclamos para efectivizar esos derechos. En el caso de los pueblos indígenas, la instrumentación del consentimiento previo, libre e informado (CPLI) cada vez que se vaya a adoptar una medida que los atañe (establecido en el mencionado Convenio) es una cuestión que ha dado lugar a no pocos debates. Varios países de la región han implementado el CPLI aunque su aplicación en el ámbito patrimonial sigue siendo restringida ${ }^{8}$. En la actualidad cuando parece haberse llegado a ciertos acuerdos sobre cómo protocolizarlo, se perfilan reclamos más directos de los pueblos indígenas sobre la propiedad legal y el control sobre el patrimonio material, así como respecto de la propiedad intelectual de los conocimientos tradicionales y expresiones culturales indígenas, los que son excepcionalmente receptados en las normas patrimoniales ${ }^{9}$. Cabe recordar que la Declara-

Una excepción lo constituye la Ley Nacional 25.517 de Argentina que establece que para realizarse investigaciones científicas que tenga por objeto el patrimonio cultural indígena deberá contarse con el expreso consentimiento de las comunidades interesadas (art. 3).

$9 \quad$ La Ley de Cultura 397 de Colombia establece que "los grupos étnicos asentados en territorios de riqueza arqueológica conservarán los derechos que efectivamente estuvieren ejerciendo sobre el patrimonio arqueológico que sea parte de su identidad cultural" (art. 13), aunque conforme a Piazzini Suárez (2013: 71) sería apropiado establecer un régimen especial de protección del patrimonio arqueológico con la participación de los entes territoriales para que esa política se haga efectiva. En Ecuador la constitución contempla el derecho de comunidades y pueblos indígenas a "mantener, recuperar, proteger, desarrollar y preservar su patrimonio cultural e histórico como parte indivisible del patrimonio del Ecuador" ción sobre los Derechos de los Pueblos Indígenas, aprobada por la Asamblea General de la ONU en 2007, y la Declaración Americana sobre los Derechos de los Pueblos Indígenas, elaborada en el seno de la OEA en 2016, han avanzado en ese sentido. Si bien estos documentos tienen el carácter de recomendaciones y no son vinculantes, la opinión dominante en la doctrina afirma el carácter obligatorio de las Declaraciones de Derechos Humanos en forma indirecta. Ello se debe a que los derechos reconocidos en ellas representan "principios generales del derecho de las naciones civilizadas" y por ende constituyen una fuente de derecho reconocida por los tribunales internacionales (Endere 2013). Ello deja abierta la posibilidad de recurrir, por ejemplo, a la Corte Interamericana de Derechos Humanos para apelar decisiones judiciales desfavorables frente a casos de violación de esos derechos.

En el contexto actual sudamericano se da un doble proceso, por un lado, se cuestiona el rol del experto y se reclama la participación en la investigación, conservación, gestión e interpretación del registro arqueológico desde fuera de la academia -cuando no el control absoluto sobre dicho patrimonio-. Por otro, y desde la propia academia, se brega por una apertura en pos de una arqueología y una gestión patrimonial más colaborativa. Si bien estos debates son parte de diferentes corrientes de pensamiento de alcance internacional (Atalay 2012; Smith y Ralph 2019), en Sudamérica ha tenido un fuerte impacto como puede observarse en los debates llevados a cabo durante las últimas Reuniones de Teoría Arqueológica de América del Sur (TAAS) que se celebra cada dos años en diferentes países de la región. En ese marco, la arqueología y el campo patrimonial está actualmente siendo sacudido desde sus cimientos por el debate decolonial (Castro-Gómez y Grosfoguel 2007, Mignolo 2007, Quijano 2014) y la necesidad de buscar miradas alternativas a la concepción occidental del patrimonio (ver Alonso Gonzalez 2015;

(art. 57 inc. 13). El Reglamento General de la Ley Orgánica de Cultura prevé la participación de pueblos indígenas en la gestión, conservación y puesta en valor de los sitios arqueológicos relacionados con su territorio (Decreto 1428 art. 70 inc. d). También se faculta al INPC para delegarles la gestión de los sitios si cuentan con condiciones formales y técnicas para su conservación (art. 71). Esta delegación es obligatoria cuando se demuestre que el sitio ha sido administrado de manera pacífica e ininterrumpida por una comunidad durante 5 años anteriores, o cuando se trate de comunidades, pueblos o nacionalidades ancestrales vinculadas al lugar (art.72). 
Curtoni 2015; Shepherd et al. 2016; LondoñoDíaz 2020, etc.).

En términos generales podría afirmarse que estos debates no han logrado tener aún un impacto significativo en las normas patrimoniales ni en las modalidades de gestión. Sin embargo, no es menos cierto que la filosofía del Buen Vivir - como un paradigma alternativo al modelo de desarrollo tradicional, caracterizado por una nueva relación de los grupos humanos con la naturaleza- ha tenido un importante reconocimiento en los sistemas normativos de algunos países, como lo demuestran las reformas constitucionales de Ecuador y Bolivia.

La filosofía del Buen Vivir se nutre de los aportes de los saberes tradicionales, especialmente los andinos enmanados de los conceptos de sumak kawsay del kichwa de Ecuador o suma qamaña (Vivir Bien) del aymara de Bolivia. Los postulados del Buen Vivir implican una serie de rupturas con el pensamiento moderno occidental que ha inspirado todo el derecho positivo. Cuestiona la naturaleza como objeto, el dualismo occidental de naturaleza y cultura, así como un devenir histórico lineal expresado por la idea de progreso (Gudynas 2011:14). El Buen Vivir implica descolonizar los saberes y respetar la diversidad de las demás culturas, sin jerarquías de una sobre otra (Estermann 2009). Como explica Gudynas (2011) existen al menos tres planos para abordar la construcción del concepto de Buen Vivir: las ideas, los discursos y las prácticas. En el primero se encuentran los cuestionamientos radicales a las bases conceptuales del desarro1lo, especialmente su apego a la ideología del progreso. Un segundo plano se refiere a los discursos y las legitimaciones de esas ideas. En el tercero se encuentran las acciones concretas, tales como los proyectos políticos de cambio, los planes gubernamentales, los marcos normativos y las formas de elaboración de alternativas al desarrollo convencional.

El Buen Vivir ha sido plasmado en las constituciones de Ecuador (2008) y de Bolivia (2009) aunque con matices diferentes. En la constitución boliviana la idea del Vivir Bien es más que nada un principio ético y moral de carácter pluricultural, ya que es tomada desde la cosmovisión de varios pueblos indígenas y todas en el mismo plano de jerarquía (ver arts. 8, 306, 313). La concepción del Buen Vivir en la constitución ecuatoriana es diferente, está comprendida en los "derechos del Buen Vivir" y luego retomada en la sección dedicada al "ré- gimen del Buen Vivir" cuyos objetivos son muy amplios. Se establece, además, que el "Buen Vivir requerirá que las personas, comunidades, pueblos y nacionalidades gocen efectivamente de sus derechos, y ejerzan responsabilidades en el marco de la interculturalidad, del respeto a sus diversidades, y de la convivencia armónica con la naturaleza" (art. 275). Es decir que el Sumak Kawsay en la constitución de Ecuador es presentado a dos niveles: como marco para un conjunto de derechos y como expresión de buena parte de la organización y ejecución de esos derechos $^{10}$ (ver Acosta y Martínez 2009, Uzeda 2009). El Régimen del Buen Vivir en esta constitución incluye un Sistema Nacional de Cultura ya que se considera a ésta como uno de los pilares del desarrollo. Una de las finalidades de este sistema es salvaguardar el patrimonio cultural (art. 377), reconociendo como parte de él a los sitios y paisajes, así como a las colecciones de valor arqueológico (art. 379) (ver Cunningham 2013). El Buen Vivir de la constitución ecuatoriana no solo considera a la Naturaleza como sujeto de derecho (art. 72) sino que emplea como sinónimos y en un mismo nivel las categorías de Naturaleza y Pachamama, con lo que le otorga valor jurídico al saber indígena. Por otro lado, considera a la restauración integral de la Naturaleza como un derecho (art. 73). Esto implica una innovación respecto de los derechos tradicionalmente considerados de tercera generación, como lo es el derecho al ambiente y al patrimonio cultural (ver Galiano-Maritan y Tamayo-Santana 2018; Salazar Rodríguez 2020). Estos casos permiten apreciar cómo es posible a través de las normas impulsar cambios en la manera de concebir, proteger y usar el patrimonio.

No obstante, este nuevo enfoque ha generado debate y críticas no sólo desde la perspectiva filosófica sino también desde el punto de vista jurídico y económico. Al respecto, Pérez Puig-Mir (2018: 106) advierte que "la diversidad de interpretaciones del Buen Vivir generan verdaderos laberintos conceptuales, collages y debates; complejizando su comprensión y, peor aún, corriendo el riesgo de desvirtuar sus contenidos, al despojarlo de su episteme ancestral para "racionalizarlo', negando su otredad, y por tanto, colonizándolo".

10 El mandato constitucional del Buen Vivir en Ecuador se intenta aplicar a través del Plan Nacional para el Buen Vivir (SENPLADES 2013). Con el cambio de gobierno en ese país, el Buen Vivir ha perdido importancia como puede observarse en el Plan Nacional 2017-2021. 
Por su parte Barié (2014: 32-33) considera que en estas constituciones el Buen Vivir no alcanza el estatus de un nuevo paradigma consolidado sino de "narrativas" que coexisten con propuestas más convencionales sobre desarrollo. Lejos de subestimarlas, reconoce "la capacidad de movilización (...) de las narrativas constitucionales y su papel en los procesos de transformación social". No obstante afirma que "sigue vigente el desafío de cómo transformar narrativas constitucionales en normas coherentes e instituciones que establezcan políticas concretas y efectivas". En igual sentido, se ha señalado que "la propuesta de buen vivir parece recuperable, pero sigue aún sin ser plenamente configurada, se encuentra en un nivel de generalidad que debe especificarse" (Tapia et al. 2020: 17). En los últimos años se ha presentado propuestas metodológicas a través de la construcción de índices e indicadores de buen vivir (ver ejemplos en Tapia et al. 2020), algunos de ellos aplicables a sitios patrimoniales (Endere y Zulaica 2015).

Finalmente, y quizás la más importante, es la cuestión de la participación ciudadana en la salvaguarda y gestión del patrimonio, por la que abogan las recomendaciones de los organismos internacionales, así como organizaciones, comunidades y grupos de todo tipo. Este es un tema sobre el que se debate mucho en los ámbitos académicos y del que nadie parece estar en desacuerdo pese a que es difícil encontrar mecanismos concretos para instrumentalizarlo en la normativa legal aplicable al patrimonio cultural ${ }^{11} \mathrm{y}$, menos aún, verlo plasmado en la práctica. Es usual que se prevea la participación en los textos constitucionales y que se contemplen mecanismos de participación en las normas ambientales (e.g. la Ley General de Ambiente 28.611 de Perú; Ley Orgánica del Ambiente 5.833 de Venezuela), o en las leyes que regulan la participación ciudadana (e.g. Ley Orgánica de Participación Ciudadana 13 de Ecuador, Ley 20.500 sobre Asociaciones y Participación Ciudadana en la Gestión Pública de Chile, Ley Federal 10.257 que rige la acción participativa en Brasil) pero es poco común que estos mecanismos se activen para temas patrimoniales y cuando se emplean es importante observar el carácter de la participación, es decir si es informativa, consultiva o

11 La Ley 530 de Patrimonio Cultural de Bolivia contempla en el sistema de gestión a las herramientas y metodologías de concertación con la población pero no las regula (art. 27). vinculante. Existen, no obstante, excepciones como la Ley 19.891 (modificada por la 21.045) que regula el Consejo Nacional de la Cultura de Chile, ya que en ella se exige la convocatoria anual a una Convención Nacional de las Culturas, las Artes y el Patrimonio con el fin de generar instancias de reflexión crítica sobre las necesidades culturales y su correlato en las políticas públicas (art 17.4).

\section{Comentarios finales}

La persistencia a través del tiempo del Modelo Tradicional caracterizado por la propiedad estatal, así como por un perfil regulatorio y persecutorio de la gestión estatal, se puede constatar como característica común en los sistemas legales analizados, junto con la incorporación de algunos suplementos temáticos -en la misma norma o en normas complementarias- como la incoporación del patrimonio subacuático, la necesidad de desarrollar planes de gestión de sitios, de implementar medidas de conservación y/o la regulación de la arqueología preventiva. Cabe destacar que esta tendencia no parece ser privativa de Sudamérica, como bien lo describe Querol, a propósito del caso español, "es el viejo (modelo) el que existe, cuando existe" en nuestros sistemas patrimoniales (Querol 2020: 517). Se comparte también como en este país la preocupación por la magnitud que ha alcanzado la arqueología preventiva y el poco impacto que ha generado en términos de aporte de información analítica publicable o publicada que permita mejorar nuestro conocimiento del pasado (ver Alonso Villa 2003; Castillo Mena 2007; Yépez 2007, etc.).

Por otra parte, la problemática indígena, en general y en relación con el patrimonio arqueológico en especial, es compleja y presenta particularidades en cada país. Pese a los avances de las últimas décadas, puede afirmarse que es mucho más lo que proclaman las normas y las políticas que lo que sucede en la realidad; abundan los discursos de reconocimiento étnico tanto como las violaciones a los derechos humanos de estos pueblos (del Pópolo 2017). Por ello, pese a que los derechos indígenas han sido reconocidos en las cartas magnas de la mayoría de los países analizados, permanece la brecha en la implementación de esos derechos como un factor clave que debe ser siempre objeto de indagación particular (ver Endere 2020a). Entre sus conquistas pueden enumerarse los nu- 
merosos casos de restituciones y repatriaciones de restos humanos que eran parte de colecciones de museos o instituciones de investigación; así como algunos casos interesantes y cada vez más numerosos de participación en la gestión de sitios y museos comunitarios (ver Delfino et al. 2012, Gianotti et al. 2015, Narváez Vargas 2019, Correa-Lau et al. 2019) o aún de manejo del patrimonio comunal (Ruiz Ballesteros 2009, Endere y Zulaica 2015). Cabe destacar que la cuestión de la repatriación de restos humanos ha tenido un impacto muy dispar en los países de la región. Mientras que en países como Argentina $y$, en menor medida Chile, ha sido un tema trascendente, en otros, con fuerte componente demográfico indígena, esas prácticas restitutorias no han ocurrido o no han alcanzado impulso. Ello en parte se debe a que en Argentina y Chile la conquista de los últimos territorios indígenas se produjo a fines del siglo XIX y comienzos del XX y que, al menos en el primero de esos países, las colecciones de restos humanos incluyen restos de identidad conocida (e.g. cráneos y/o esqueletos de los principales jefes indígenas que fueron parte de la contienda). En Argentina los primeros reclamos datan de los años 1970s y fueron efectuados por los propios descendientes. Otro factor decisivo es el grado de recepción que estos reclamos han tenido en el ámbito socio-político y en el académico / museológico de cada país. En no pocas ocasiones las repatriaciones se produjeron por iniciativa de los propios museos, institutos y/ gobiernos sin que mediara reclamo previo (ver Endere 2020b; Arthur y Ayala 2021). Múltiples factores influyen en estas cuestiones cuyo análisis excede los objetivos de este trabajo, entre los que pueden mencionarse el desconocimiento de la existencia de esas colecciones por parte de las comunidades y la prioridad que tienen otros temas en la agenda indígena como el acceso a condiciones de vida digna y la posesión de las tierras que tradicionalmente ocupaban. Finalmente, existen cuestiones más profundas y complejas vinculadas con los diversos procesos de construcción de las identidades en estas naciones multiétnicas (ver Rivera Cusicanqui 2010), que sin duda operan en la activación o no de los procesos de reclamo y de repatriación.

Respecto del patrimonio arqueológico de la región, se destaca por su notable valor y por haber estado históricamente amenazado. En efecto, los bienes culturales que lo componen, sean muebles o inmuebles, son afectados por las recurrentes crisis políticas, sociales y eco- nómicas $^{12}$ que impiden la continuidad de las políticas y la posibilidad de monitorear en terreno lo que ocurre con ellos. Otros factores de riesgo que pueden mencionarse son algunas formas tradicionales de uso del territorio y sus recursos que son incompatibles con la preservación de los sitios, los procesos de urbanización descontrolada, así como los programas de rehabilitación y regeneración de áreas patrimoniales con fines turísticos terminan generando procesos de gentrificación, desplazamiento y desposesión de los pobladores tradicionales (Cabrera-Jara 2019). En la actualidad se suma, además, la Pandemia de COVID-19 cuyas consecuencias aun no conocemos pero estimamos graves. Las exploraciones con detectores de metales, por ejemplo, han proliferado como actividad recreativa durante las sucesivas cuarentenas, al tiempo que museos y lugares de guarda permanecen cerrados y sin monitoreo.

Como puede imaginarse, la salvaguarda de este patrimonio es impensable en los vastos territorios sudamericanos sin la anuencia de los ciudadanos, quienes, en general, están lejos de considerar al patrimonio arqueológico como algo de su incumbencia. Como señala Querol (2020: 577), "hay mucha distancia entre lo que la gente piensa y lo que ocurre con la gestión y naturaleza de los bienes culturales. Esto significa que la posibilidad de que la sociedad participe en esta última es muy escasa, ya que vive de espalda a ellos". En este punto es cuando la participación se vuelve un tema crítico, por un lado, es un imperativo en el marco del actual "paradigma participativo del patrimonio" (ver Sánchez-Carretero y Jiménez-Esquinas 2016; Jiménez-Esquinas 2020), al que se resisten a menudo los funcionarios, o bien recurren a estrategias para montar parodias de participación a fin de legitimar decisiones que ya habían sido previamente adoptadas. Por otro, es difícil movilizar a la sociedad respecto de temas que están lejos de su cotidianeidad y de sus preocupaciones actuales por estar ligadas a un pasado tan lejano en el tiempo como desconocido. No obstante, los temas (y materialidades) implicados con la arqueología no siempre pertenecen a "un pasado tan lejano" sino a uno relativamente reciente, cuyas huellas, memoria y presencia son tan valiosas como aquellas prehispánicas o

\footnotetext{
El Plan de Acción para América Latina y el Caribe (20142024), adoptado por el Comité del Patrimonio Mundial en 2013 considera al patrimonio arqueológico como uno de los temas prioritarios para la región, dado los desafíos que enfrenta.
} 
coloniales. La arqueología histórica y urbana latinoamericanas han efectuado un aporte en la recuperación del pasado de comunidades nativas e inmigrantes, incluidas las afroamericanas (Therrien 2013). A su vez, la denominada "arqueología de la violencia" ha tenido un rol clave en la recuperación de la evidencia material y la resignificación de los sitios de la memoria, como los centros clandestinos de detención de los gobiernos dictatoriales del siglo XX, entre otros ejemplos (Zarankin et al. 2012).

La relación de cada sociedad con su pasado debe ser analizada en cada contexto y a nivel local, lo que probablemente dará por resultado una enorme diversidad de situaciones, ya que aún tratándose de comunidades pequeñas dentro de una misma provincia o región su identificación con el pasado ancestral puede diferir considerablemente. De todos modos, lo que queda claro es que la consolidación de un nuevo modelo de protección del patrimonio que se oriente a una gestión más plural y participativa demanda sortear no pocos desafíos, que van mucho más allá que la mera instrumentalización legal de los mecanismos participativos.

\section{Bibliografía}

Acosta, A.; Martínez, E. (comp.) (2009): El Buen Vivir. Una vía para el desarrollo. Abya Yala, Quito.

Alonso González, P. (2015): Patrimonio y ontologías múltiples: hacia la coproducción del patrimonio cultural. Patrimonio y Multivocalidad Teoría, práctica y experiencias en torno a la construcción del conocimiento en Patrimonio (C. Gianotti García; D. Barreiro Martínez; B. Vienni Baptista, eds.). Universidad de la República, Montevideo: 179-198.

Alonso Villa, F. (2003): Arqueología de rescate y desarrollo sostenible en Colombia: crítica a un vínculo instrumental. Arqueología al desnudo. Reflexiones sobre la práctica disciplinaria (C. Gnecco; Piazzini, E. eds.). Universidad del Cauca, Popayán: 320 a 357.

Arthur, J.; Ayala, P. (2021): El regreso de los ancestros. Un movimiento indígena hacia la reparación, reconciliación y sanación. Línea editorial del Servicio Nacional de Patrimonio Cultural de Chile, Santiago.

Atalay, S. (2012): Community-based archaeology: research with, by, and for indigenous and local communities. University of California Press, Los Angeles.

Barié, C. (2003): Pueblos indígenas y derechos constitucionales en América Latina: un panorama. Instituto Indigenista Interamericano, México.

Barié, C. (2014): Nuevas narrativas constitucionales en Bolivia y Ecuador: el buen vivir y los derechos de la naturaleza. Latinoamérica, 59 (2): 9-40.

Cantar, N.; Endere, M.; Zulaica, M. (2020): La "arqueología" de la sustentabilidad en la concepción del patrimonio cultural. Revista de Estudios Sociales, 75: 71-86.

Cabrera-Jara, N. (2019): Gentrificación en áreas patrimoniales latinoamericanas: cuestionamiento ético desde el caso de Cuenca, Ecuador. Urbe. Revista Brasileira de Gestão Urbana, 11. http://doi. org/10.1590/2175-3369.011.e20180201.

Carámbula, G. (2007): Miradas a las convenciones de la UNESCO en Uruguay. Legislaciones en el MERCOSUR relativas a las Convenciones de Cultura aprobadas por la UNESCO. Estudio de la situación actual en Argentina, Brasil, Paraguay y Uruguay, UNESCO, Oficina Regional de Ciencia para América Latina y El Caribe, Montevideo: 119-148.

Castillo Mena, A. (2007): El anuario de actuaciones arqueológicas y paleontológicas de la Comunidad de Madrid. 2002 y 2003: Análisis de cifras. Actas de las segundas jornadas de Patrimonio Arqueológico en la Comunidad de Madrid, Madrid: 163-179.

Castro-Gómez, S.; Grosfoguel R. (eds.) (2007): El giro decolonial. Reflexiones para una diversidad epistémica más allá del capitalismo global. Iesco-Pensar-Siglo del Hombre Editores, Bogotá.

Correa-Lau, J.; Carmona, J.; Carmona, G.; Castro, V.; Santoro, C. (2019): $\quad$ Entre Pablo Neruda y Rigoberta Menchú. Representaciones del Pasado Precolombino en Museos de Chile. Chungará, Revista de Antropología Chilena, 51(2): 191-200.

Cunningham, M. (2013): La Cultura: Pilar de desarrollo para el Buen Vivir. Cultura y Desarrollo, 9: 28-37.

Curtoni, R. (2015). Multivocalidad, geopolíticas y patrimonio. Prácticas situadas entre los rankülches del centro de Argentina. Patrimonio y Multivocalidad Teoría, práctica y experiencias en torno a la construcción del conocimiento en Patrimonio (C. Gianotti García; D. Barreiro Martínez; B. Vienni Baptista, eds.). Universidad de la República, Montevideo: 95-114. 
Delfino, D.; Barale, A.; Díaz, A.; Dupuy, S.; Espiro, V.; Pisani, G.; Albert, Y.; Cuello, C.; Gamboa, M.; Gonzalez, C. (2012). Confluencias entre el Museo Integral de la Reserva de Biosfera de Laguna Blanca y una Arqueología Socialmente Útil en la Puna catamarqueña. III Encuentro de Museos Universitarios del Mercosur. Museos: memoria + creatividad = cambio social. [URL: https://www.researchgate.net/ publication/312970200_Confluencias_entre_el_Museo_Integral_de la_Reserva_de_Biosfera_de Laguna_Blanca_y_una_Arqueologia_Socialmente_Util_en_la_Puna_catamarquena].Acceso 09/02/2021.

del Pópolo, F. (ed.) (2017): Los pueblos indígenas en América (Abya Yala). Desafios para la igualdad en la diversidad. CEPAL, Santiago de Chile.

Endere, M. (2009): Algunas Reflexiones acerca del Patrimonio. Patrimonio, Ciencia y Comunidad. Su abordaje en los Partidos de Azul, Tandil y Olavarría (M. Endere; J. Prado, eds.). UNCPBA, Olavarría: 19-48.

Endere, M. (2013): Recaudos legales y éticos aplicables a los profesionales que trabajan con el patrimonio arqueológico y bioantropológico. Temas de patrimonio cultural (M. Endere; Chaparro, M.; Mariano, C., eds.). UNICEN, Tandil: 12-33.

Endere (2020a): Latin America: Indigenous Peoples' Rights. Encyclopedia of Global Archaeology. (C. Smith, ed.). Springer, Cham. https://doi.org/10.1007/978-3-319-51726-1.

Endere (2020b): Restitution Policies in Argentina: The Role of The State, Indigenous Peoples, Museums, and Researchers. The Routledge Companion to indigenous repatriation. Return, Reconcile, Renew, (C. Fforde, McKeown, T,; Keeler, H., eds.). Routledge. Londres:188-207.

Endere, M.; Cali, P.; Funari, P. (2011): Archaeology and Indigenous communities. A comparative study of Argentinean and Brazilian legislation. Indigenous peoples and Archaeology in Latin America, (C. Gnecco; P. Ayala, eds.). Left Coast Press, Walnut Creek: 159-177.

Endere, M.; Ayala, P. (2012): Normativa legal, recaudos éticos y práctica arqueológica. Un estudio comparativo de Argentina y Chile. Chungará. Revista de Antropología Chilena, 44(1): 39-58.

Endere, M.; Zulaica; M. (2015): Sustentabilidad Socio-Cultural y Buen Vivir en Sitios Patrimoniales: Evaluación del Caso Agua Blanca, Ecuador. Ambiente \& Sociedade, 18(4):265-290.

Endere, M.; Bonnin, M. (2020): Actores sociales, derechos, roles e intereses involucrados en la concepción y el manejo del patrimonio arqueológico argentino. Prácticas históricas de coleccionismo y desafíos actuales. Revista d'Arqueologia de Ponent, 30: 241-253.

Estermann, J. (2009): Colonialidad, descolonización e interculturalidad. Apuntes desde la filosofía intercultural. Interculturalidad crítica y descolonización. Fundamentos para el debate, (D. Mora ed.). Convenio A. Bello, Instituto Internacional Integración, La Paz: 51-7.

Galiano-Maritan, G.; Tamayo-Santana, G. (2018): Análisis constitucional de los derechos personalísimos y su relación con los derechos del buen vivir en la Constitución de Ecuador. Revista de Derecho Privado, 34: 123-156.

Gianotti, C.; Villamarzo, E.; Blasco, J.; Lamas, G.; Gentile, B.; Bica, C. (2015): Paisaje y patrimonio como espacios de construcción multivocal en el Área Protegida de Laguna de Rocha. Patrimonio y Multivocalidad Teoría, práctica y experiencias en torno a la construcción del conocimiento en Patrimonio (C. Gianotti García; D. Barreiro Martínez; B. Vienni Baptista, eds.). Universidad de la República, Montevideo: 161-177.

Gudynas, E. (2011): Buen vivir: Germinando alternativas al desarrollo. América Latina en Movimiento, 462: $1-20$.

Hobsbawm, E.; Ranger, T. (eds.) (1983): The Invention of Tradition. Cambridge University Press, Cambridge.

ICOMOS (International Council of Monuments and Sites) (2008): Carta de Itinerarios Culturales. [URL: https://www.icomos.org/images/DOCUMENTS/Charters/culturalroutes_sp.pdf]. Acceso 09/02/2021.

Jiménez-Esquinas, G. (2020): El papel de las comunidades en el patrimonio: una reflexión en torno al patrimonio arqueológico. Revista PH, 101: 100-121.

Levrand, N. (2016): La regulación del patrimonio cultural en Argentina Dominio, competencias y significaciones. Tesis doctoral. Facultad de Ciencias Jurídicas y Sociales, Universidad Nacional del Litoral, Santa Fe.

Levrand, N.; Endere, M. (2020): Nuevas categorías patrimoniales. La incidencia del soft law en la reciente reforma a la ley de patrimonio histórico y artístico de Argentina. Revista Direito GV, 16(2). DOI: $10.1590 / 2317-6172201960$

Londoño-Díaz, W. (2020): La Arqueología Latinoamericana en la ruta de la Decolonialidad. Boletín Antropológico, 38(100): 286-313. 
Meskell, L. (2018): Heritage, gentrification, participation: Remaking urban landscapes in the name of culture and historic preservation. International Journal of Heritage Studies. DOI: $10.1080 / 13527258.2018 .1542334$.

Mignolo, W. (2007): La idea de América Latina. La herida colonial y la opción decolonial. Gedisa, Barcelona.

Narváez Vargas, L. (2019): El Museo Túcume y la Nueva Museología. Chungará. Revista de Antropología Chilena, 51(2): 291-304.

Prats, Ll. (2007): Antropología y patrimonio. Editorial Ariel, Barcelona.

Pérez Puig-Mir, N. (2018): Configuración jurídica, contenido y protección del Buen Vivir a la luz de la constitución ecuatoriana. Revista Jurídica, 31: 93-109.

Piazzini Suárez, C. (2017): Patrimonio arqueológico en Colombia: una interpretación del proceso de conformación del marco legal actual. Bienes arqueológicos: una lectura transversal sobe legislación y políticas culturales - Argentina, Colombia, China, Francia, Gran Bretaña, e Italia, (C. Piazzini; L. González Jaramillo, eds.). Universidad de Los Andes, Bogotá: 57-74.

Querol, M. (2020): Manual de Gestión del Patrimonio Cultural. 2da. ed. actualizada. Ediciones Akal, Madrid.

Quijano, A. (2014). Cuestiones y horizontes: de la dependencia histórico-estructural a la colonialidad/ descolonialidad del poder. CLACSO, Buenos Aires.

Ramírez Arias, S.; Saldarriaga Ramírez, C. (2013): Usos y abusos del paisaje cultural cafetero: una reflexión desde el concepto de patrimonio. Jangwa Pana, 12(1): 115-128.

Rivera Cusicanqui, S. (2010): Violencias (re)encubiertas en Bolivia. Piedra Rota, La Paz.

Ruiz Ballesteros, E. (2009): Agua Blanca. Comunidad y turismo en el Pacifico ecuatorial. Abya-Yala, Quito.

Salazar Rodríguez, A. (2020): Buen Vivir, Paradigma legal ineludible para todo ser humano. El Buen Vivir desde la perspectiva económica y jurídica, (R. Tapia Vega, R. Cañedo Villarreal, P. Mochi Alemán; T. González Rivera, coord.). Universidad Santiago de Cali - Universidad Autónoma de Guerrero, Cali y Guerrero: 32-64.

Saladino, A. (2019): Arqueología y sociedad en Brasil: una mirada sobre la socialización y preservación del patrimonio arqueológico desde la educación patrimonial. Revista Otarq, 4: 251-266.

Saladino, A.; Moraes Wichers, C. (2015): La preservación del patrimonio arqueológico en Brasil: Un panorama sobre la actuación del Instituto del Patrimonio Histórico y Artístico Nacional (IPHAN). Memorias. Revista Digital de Historia y Arqueología desde el Caribe, 27: 36-71.

Sánchez-Carretero, C.; Jiménez- Esquinas G. (2016): Relaciones entre actores patrimoniales: gobernanza patrimonial, modelos neoliberales y procesos participativos. Revista PH, 90: 190-197. [URL:http:// www.iaph.es/revistaph/index.php/revistaph/article/view/3827]. Acceso: 06/10/2020.

SENPLADES (2013): Plan Nacional de Desarrollo / Plan Nacional para el Buen Vivir 2013-2017. Secretaría Nacional de Planificación y Desarrollo, Quito.

Shepherd, N.; Gnecco, C.; Haber, A. (2016): Arqueología y decolonialidad. Ediciones del Signo, Buenos Aires.

Silva Pérez, R.; Fernández Salinas, V. (2015): Los paisajes culturales de Unesco desde la perspectiva de América Latina y el Caribe. Conceptualizaciones, situaciones y potencialidades. Revista INVI, 30 (85): 181-212.

Tapia Vega, R.; Cañedo Villarreal, R.; Mochi Alemán, P.; González Rivera, T. (coord. ) (2020): El Buen Vivir desde la perspectiva económica y jurídica. Universidad Santiago de Cali - Universidad Autónoma de Guerrero, Cali y Guerrero.

Therrien, M. (2013): Arqueología histórica, políticas y prácticas culturales en Colombia. Revista Teoría y práctica de la Arqueología Histórica Latinoamericana, II(2): 11-26.

UNESCO (2005): Textos fundamentales de la Convención de 2005 sobre la protección y la promoción de la diversidad de las expresiones culturales. UNESCO, París. [URL: https://unesdoc.unesco.org/ ark:/48223/pf0000225383_spa45]. Acceso 09/02/2021.

UNESCO (2008): Operational Guidelines for the Implementation of the World Heritage Convention. UNESCO, París. [URL: https://whc.unesco.org/archive/opguide08-en.pdf]. Acceso 09/02/2021.

UNESCO (2018): La cultura para la Agenda 2030. UNESCO, París.

Uzeda V. (2009): Suma qamaña. Visiones indígenas y desarrollo. Traspatios, 1: 33-51.

Valdez, F. (2010): La Investigación Arqueológica en el Ecuador: Reflexiones para un Debate. INPC. Revista del Patrimonio Cultural del Ecuador, 2: 6-23. 
Wood, S.; Jones, S.; Johnson, J.; Brauman, K., Chaplin-Kramer, R; Zhang, W. (2018): Distilling the Role of Ecosystem Services in the Sustainable Development Goals. Ecosystem Services, 29: 70-82.

Yépez, A. (2007): ¿Arqueología de Salvamento o Arqueología Clientelar? El Manejo del Patrimonio Cultural en la Amazonía Ecuatoriana. Antropología. Cuadernos de Investigación, 7: 37-58.

Zarankin, A.; Salerno, M.; Perosino, M. (comp.) (2012): Historias desaparecidas: arqueología, memoria y violencia política. Encuentro Grupo Editor, Córdoba. 
